\title{
Predictors of quality of life and survival following Gamma Knife surgery for lung cancer brain metastases: a prospective study
}

\author{
Sidsel Bragstad, MSc, RN, ${ }^{1,2}$ Marianne Flatebø, RN, ${ }^{3}$ Gerd Karin Natvig, PhD, RN, ${ }^{2}$ \\ Geir Egil Eide, DrPhil CandReal, ${ }^{2,4}$ Geir Olve Skeie, PhD, MD, ${ }^{5}$ Maziar Behbahani, MD, FRSC(SN), ${ }^{1,6}$ \\ Paal-Henning Pedersen, PhD, MD, ${ }^{1,7}$ Per Øyvind Enger, PhD, MD, ${ }^{1,8}$ and \\ Bente Sandvei Skeie, PhD, MD1,7
}

\begin{abstract}
Departments of ${ }^{1}$ Neurosurgery, ${ }^{3}$ Research and Development, and ${ }^{5}$ Neurology; ${ }^{4}$ Centre for Clinical Research, Haukeland University Hospital; ${ }^{2}$ Department of Global Public Health and Primary Care; ${ }^{7}$ Institute of Clinical Medicine K1; ${ }^{8}$ Oncomatrix, Institute of Biomedicine, University of Bergen; and ${ }^{6}$ Department of Neurosurgery, Stavanger University Hospital, Stavanger, Norway
\end{abstract}

OBJECTIVE Lung cancer (LC) patients who develop brain metastases (BMs) have a poor prognosis. Estimations of survival and risk of treatment-related deterioration in quality of life (QOL) are important when deciding on treatment. Although we know of several prognostic factors for LC patients with BMs, the role of QOL has not been established. Authors of this study set out to evaluate changes in QOL following Gamma Knife surgery (GKS) for BMs in LC patients and QOL as a prognostic factor for survival.

METHODS Forty-four of 48 consecutive LC patients with BMs underwent GKS in the period from May 2010 to September 2011, and their QOL was prospectively assessed before and 1, 3, 6, 9, and 12 months after GKS by using the Functional Assessment of Cancer Therapy-Brain (FACT-BR) questionnaire. A mixed linear regression model was used to identify potential predictive factors for QOL and to assess the effect of GKS and the disease course on QOL at follow-up.

RESULTS Mean QOL as measured by the brain cancer subscale (BRCS) of the FACT-BR remained stable from baseline (score 53.0) up to 12 months post-GKS (57.1; $p=0.624)$. The BRCS score improved for 32 patients $(72.3 \%)$ with a total BM volume $\leq 5 \mathrm{~cm}^{3}$. Mean improvement in these patients was 0.45 points each month of follow-up, compared to a decline of 0.50 points each month despite GKS treatment in patients with BM volumes $>5 \mathrm{~cm}^{3}(p=0.04)$. Asymptomatic BMs $(p=0.01)$, a lower recursive partitioning analysis (RPA) classification $(p=0.04)$, and a higher Karnofsky Performance Scale (KPS) score $(p<0.01)$ at baseline were predictors for a high, stable QOL after GKS. After multivariate analysis, a high KPS score $(p<0.01)$ remained the only positive predictor of a high, stable QOL post-GKS.

Median survival post-GKS was 5.6 months (95\% CI 1.0-10.3). A higher BRCS score $(p=0.01)$, higher KPS score ( $p$ $=0.01)$, female sex $(p=0.01)$, and the absence of liver $(p=0.02)$, adrenal $(p=0.02)$, and bone metastases $(p=0.03)$ predicted longer survival in unadjusted models. However, in multivariate analyses, a higher BRCS score $(p<0.01)$, female sex $(p=0.01)$, and the absence of bone metastases $(p=0.02)$ at GKS remained significant predictors. Finally, the BRCS score's predictive value for survival was compared with the values for the variables behind well-known prognostic indices: age, KPS score, extracranial disease status, and number and volume of BMs. Both BRCS score $(p=0.01)$ and BM volume $(p=0.05)$ remained significant predictors for survival in the final model.

CONCLUSIONS Patient-reported QOL according to the BRCS is a predictor of survival in patients with BMs and may be helpful in deciding on the optimal treatment. Gamma Knife surgery is a safe and effective therapeutic modality that

ABBREVIATIONS BM = brain metastasis; BRCS = brain cancer subscale; DS-GPA = diagnosis-specific Graded Prognostic Assessment; EGFR = epidermal growth factor receptor; EORTC = European Organisation for Research and Treatment of Cancer; EWB = emotional well-being; FACT-BR = Functional Assessment of Cancer Therapy-Brain; FACT-G = FACT general version; FWB = functional well-being; GKS = Gamma Knife surgery; KPS = Karnofsky Performance Scale; LC = lung cancer; MLM = mixed linear model; NSCLC = non-small cell lung cancer; PWB = physical well-being; $\mathrm{QOL}=$ quality of life; RPA = recursive partitioning analysis; RTOG = Radiation Therapy Oncology Group; SCLC = small cell lung cancer; SIR = prognostic score index for radiosurgery; SRS = stereotactic radiosurgery; SWB = social well-being; TOI = trial outcome index; WBRT = whole-brain radiation therapy.

SUBMITTED June 24, 2016. ACCEPTED February 9, 2017.

INCLUDE WHEN CITING Published online August 18, 2017; DOI: 10.3171/2017.2.JNS161659. 
improves QOL for LC patients with a BM volume $\leq 5 \mathrm{~cm}^{3}$ at treatment. Careful follow-up and salvage therapy on demand seem to prevent worsening of $\mathrm{QOL}$ due to relapse of BMs.

https://thejns.org/doi/abs/10.3171/2017.2.JNS161659

KEY WORDS Gamma Knife surgery; stereotactic radiosurgery; quality of life; Functional Assessment of Cancer Therapy-Brain subscore; survival; brain metastases; lung cancer; oncology

$\mathrm{L}$ UNG cancer (LC) is the most common origin of brain metastases (BMs), ${ }^{20}$ and non-small cell lung cancer (NSCLC) is the biggest subgroup, accounting for $85 \%-90 \%$ of cases..$^{32}$ Optimal treatment for these patients, however, is still debated. Importantly, the prognosis is poor ${ }^{17,34}$ and treatment is palliative. Estimations of survival and risk of treatment-related deterioration in quality of life (QOL) for individual patients with BMs are important when obtaining informed consent and selecting appropriate and optimal cost-effective treatment regimens.

Several prognostic factors for survival in patients with BMs have been identified: age, sex, symptoms, Karnofsky Performance Scale (KPS) score, number of BMs, volume of BMs, tumor subtype, stability of disease, and extracranial metastases. Based on these factors, prognostic indices of varying complexity have been developed including the recursive partitioning analysis (RPA) classification, ${ }^{8,29,41}$ the diagnosis-specific Graded Prognostic Assessment (DSGPA), ${ }^{33}$ and the prognostic score index for radiosurgery (SIR). ${ }^{39}$ Despite these indices, accurate estimation of survival for each patient in the clinical setting is challenging. ${ }^{21}$

A common factor in all prognostic indices is the KPS, which is sometimes described as a measure of QOL but differs from QOL measures in several ways. Firstly, the KPS is not patient reported. A patient's self-assessment often differs from the assessment of health care staff, and measuring QOL from the patient's perspective is imperative. ${ }^{14}$ Secondly, the KPS measures general function and lacks the emotional, social, and disease-specific dimensions of common QOL questionnaires..$^{23}$ The intention of the term "health-related quality of life" was to focus on the impact of health, illness, and treatment on a person's QOL. ${ }^{15}$ A decline in QOL may be due to the adverse effects of treatment or factors related to progression of a disease both intra- and extracranially.

The 2 prospective randomized controlled studies evaluating QOL after stereotactic radiosurgery (SRS) alone or SRS followed by whole-brain radiation therapy (WBRT) for BMs, ${ }^{6}$ or evaluating adjuvant WBRT after surgery or SRS for BMs, ${ }^{31}$ have concluded that local treatment alone is the preferred therapeutic option with a positive impact on QOL. Few studies have prospectively evaluated QOL after SRS for BMs from a specific tumor type, as recommended by the European Organisation for Research and Treatment of Cancer (EORTC) Brain Metastases Strategic Meeting in 2012..$^{27}$ Therefore, we aimed to identify potential baseline predictors of QOL changes reported by LC patients and to evaluate how the disease course and Gamma Knife surgery (GKS) affected their QOL during follow-up. The secondary aim was to investigate QOL as a predictor of survival in patients with BMs from primary LC treated with GKS, when adjustments were made for known prognostic factors.

\section{Methods \\ Study Design}

We conducted a longitudinal prospective study with patient-reported QOL after GKS for BMs in LC patients and survival according to QOL at GKS as end points. In the period from May 2010 until September 2011, all patients with BMs who had been referred for GKS at Haukeland University Hospital, which is the national center for GKS, were evaluated for inclusion in this study. Inclusion criteria were as follows: 1) primary lung cancer (NSCLC or SCLC); 2) age $>18$ years; 3 ) KPS score $\geq 70$ at the time of referral; 4) total tumor volume $\leq 25 \mathrm{~cm}^{3}$; and 5) $\leq 6 \mathrm{BMs}$. Exclusion criteria were 1) unfeasible GKS treatment or an overriding indication for surgery because of high intracranial pressure or the need to obtain a histological diagnosis; 2) prior diagnosis of a primary brain tumor; and 3) prior treatment of BMs with GKS.

In a consecutive series of 115 patients, 48 had primary LC and were eligible for the study. Of these 48 patients, 3 refused to participate and 1 patient did not meet the inclusion criteria, leaving 44 patients with a total of $102 \mathrm{BMs}$ in the study. The study was closed when the last patient was followed up for 1 year.

\section{Study Procedures}

On the day before treatment when the patients arrived, study nurses collected clinical data including age, sex, lung cancer subtype, symptoms from BMs, extracranial lesions, steroid medication, prior treatments for the primary cancer, and prior treatments for BMs. The KPS (Scores 0-100) and RPA (Classes 1-3) were scored. Details on mutation status and targeted therapy were collected retrospectively.

Gamma Knife surgery was performed using Leksell Perfexion and the GammaPlan software (both Elekta Instruments AB). The mean margin dose was $20.4 \mathrm{~Gy}$ (range $16-25 \mathrm{~Gy}$ ) with a mean tumor coverage of $98.6 \%$ (range 95\%-100\%). The number and volume of BMs and the extent of peritumoral edema were registered at treatment.

\section{QOL Instrument}

Quality of life was measured by self-report before treatment and at 1, 3, 6, 9, and 12 months after GKS. Follow-up questionnaires in the form of the Functional Assessment of Cancer Therapy-Brain (FACT-BR, version 4) were sent by post. A Norwegian version has been published. ${ }^{3}$ 
For cancer patients, there are disease-specific subscales for use with the general version (FACT-G). The FACTBR has been validated for patients with BMs. ${ }^{35}$ It consists of 5 domains: physical well-being (PWB; 7 items), social well-being (SWB; 7 items), emotional well-being (EWB; 6 items), functional well-being (FWB; 7 items), and a brain cancer subscale (BRCS; 23 items regarding neurological concerns, score range 0-76). Responses to the items are rated on a 5-point Likert scale ranging from 0 (not at all) to 4 (very much). The higher the patient score, the better the QOL.

At the end of the study, QOL was calculated in accordance with the FACT-BR guidelines, ${ }^{7}$ that is, FACT-G (score range 0-108) $=\mathrm{PWB}+\mathrm{SWB}+\mathrm{EWB}+\mathrm{FWB}$; Total (score range $0-184)=$ FACT $-\mathrm{G}+\mathrm{BRCS}$; and trial outcome index (TOI; score range 0-132) $=$ PWB + FWB + BRCS. A cutoff value of $<45$ versus $\geq 45$ for the BRCS was used to separate one-third of the patients with the lowest BRCS scores. One patient did not complete all of the FACT-BR questions at baseline.

Clinical outcome (symptoms, complications, steroid treatment, and extracranial disease status) was assessed by telephone interview at 1 month and then every 3rd month after GKS.

\section{Local Tumor Control}

Gadolinium-enhanced MRI of the brain was performed at the time of GKS and at 1, 3, 6, 9, and 12 months after GKS, and the images were exported to GammaPlan for evaluation of the changes in tumor volume and the surrounding edema. Local control was graded according to the Response Evaluation Criteria in Solid Tumors (RECIST) criteria: ${ }^{13,26,36}$ complete response, disappearance of the tumor; partial response, at least $30 \%$ decrease in tumor volume; and stable tumor, less than $30 \%$ decrease in tumor volume and less than $20 \%$ increase in tumor volume. Local failure was defined as at least a $20 \%$ increase in the tumor volume. Adverse events due to radiation were graded based on the Common Toxicity Criteria from the Radiation Therapy Oncology Group (RTOG). ${ }^{38}$

\section{Overall and Progression-Free Survival}

Survival data and cause of death were recorded from the medical notes. Progression-free survival, defined as the length of time the GKS-treated lesions remained stable or reduced in size, was recorded.

\section{Ethical Considerations}

Ethics approval was obtained from the Regional Ethical Committee for Medical Research, and signed written informed consent was obtained from the patients.

\section{Statistical Analysis}

Descriptive statistics quantified patient and treatment characteristics, and Kaplan-Meier survival analysis was performed to calculate overall and progression-free survival.

\section{Part 1}

For each QOL scale (PWB, SWB, FWB, EWB, FACT-
G, BRCS, Total, and TOI), a set of mixed linear regression analyse ${ }^{5}$ was performed using the 6 study time points $(0$, $1,3,6,9$, and 12 months) as within-patient factors, assuming an autoregressive correlation structure of first order (AR1). In all models, the time since GKS, age, and sex were included as covariates.

Analyses of the BRCS were performed by adding only one of the other covariates at a time (KPS score, RPA class, symptomatic BMs, prior treatment for BMs) and testing any interactions between each of these covariates and time since surgery. Finally, all the variables were included in a starting model, and then exclusion of the least significant variable from the model in a backward stepwise manner was performed until only time, age, sex (forced into the models), and covariates with $p \leq 0.05$ for removal remained. To this model, we added the most significant interactions with $\mathrm{p} \leq 0.05$ between time and the other variables in a forward stepwise manner.

Variables recorded before GKS (coding) were sex (0: male, 1: female), age (years, continuous), time since GKS (months, continuous), number of BMs (continuous), total BM volume (continuous), peritumoral edema (0: none/ minimal, 1: moderate/extensive), localization (0: cerebral lobes, 1: cerebellum, 2: pons/brainstem), primary cancer (0: NSCLC, 1: SCLC), extracranial metastases (0: none, 1: lung, 2: liver, 3: bone, 4: adrenal, 5: lymph nodes), only BM (0: yes, 1: no), RPA class (0: RPA 1, 1: RPA 2, 2; RPA $3)$, KPS score (continuous), pretreatment symptoms from BMs (0: none; 1: yes, but resolved on steroids before GKS; 2: yes), seizures (0: yes, $1:$ no), cognitive deficits ( 0 : yes, 1 : no), extremity paresis ( 0 : yes, $1:$ no), cranial nerve deficits (0: yes, 1: no), other focal symptoms (0: yes, 1: no), previous treatment for BM (0: none, 1: surgery, 2: WBRT, 3: surgery + WBRT), targeted therapy (0: yes, 1 : no), mutation status (0: positive, 1: negative), and SRS integral dose to the $\operatorname{cranium}^{37}(0: \leq 3,1:>3)$.

We used a mixed linear model (MLM), which allows for the inclusion of subjects responding only at baseline or only post-GKS.

\section{Part 2}

Unadjusted Cox regression survival analysis was performed for known prognostic factors: age, sex, NSCLC/ SCLC, number of BMs (1, 2, 3, > 3), BM location (at least $1 \mathrm{BM}$ in cerebellum and/or brainstem vs cerebrum only), $\mathrm{BM}$ volume (>13 $\mathrm{cm}^{3}$ vs $5-13 \mathrm{~cm}^{3}$ vs $\left.<5 \mathrm{~cm}^{3}\right)$, absence/ presence of extracranial metastases, liver metastases, bone metastases, adrenal metastases, lymph node metastases, KPS score ( $\leq 70$ vs $>70)$, RPA class, and FACT-BR score (8 subscores). All significant variables were included in an adjusted model before exclusion of the least significant variable in a backward stepwise manner was performed until only covariates with $\mathrm{p} \leq 0.05$ for removal remained (final model). The predictive value of QOL and other variables for risk of death is reported as a hazard ratio using the Cox proportional-hazards regression model. Actuarial survival rates at 3 and 6 months post-GKS according to significant baseline predictors for survival were calculated using survival tables from the Kaplan-Meier analyses. Finally, we compared the predictive values for survival in a Cox regression model for known prognostic indices (RPA, 
DS-GPA, and SIR), including the variables they are constructed from, and BRCS.

Statistical significance was set at $\mathrm{p} \leq 0.05$. The statistical analyses were performed using SPSS version 20 (IBM Corp.).

\section{Results}

Clinical and tumor-specific characteristics are given in Table 1. Epidermal growth factor receptor (EGFR) mutation status was positive in 3 , negative in 24 , and unknown in 17 of the 44 patients. Targeted therapy was used in all 3 EGFR-positive patients and in 3 patients with unknown mutation status.

\section{Overall and Progression-Free Survival}

At the end of the study, 11 (25\%) of 44 patients were still alive and censored. The time from primary diagnosis to GKS was a mean of 7 months (range 0.5-31 months). Median survival post-GKS was 5.6 months (95\% CI 1.010.3; Fig. 1A). Only 3 patients (7\%) died of neurological causes, 1 of them within the 12 months during which QOL was monitored.

Follow-up MRI studies after GKS were available for 39 (88.6\%) of the 44 patients; these patients lived at least 1 month post-GKS. Overall progression-free survival was $87.2 \%$, with a 1-year progression-free survival rate of 80.4\% (Fig. 1B). Pseudoprogression (RTOG Grades 1 and 2) was registered for 1 or more of the treated lesions in 7 (18\%) of the 39 patients. Distant failures (mean of 2.4 lesions, range 1-10 lesions) were seen in $22(56 \%)$ of the 39 patients; 15 patients $(68 \%)$ were retreated with $1-3$ GKSs, $4(18 \%)$ received WBRT, and 3 (14\%) received supportive care only.

\section{Clinical Outcome}

Clinical outcome data at 1, 3, 6, 9, and 12 months postGKS were available for 39 responders (100\%) among 39 alive patients, 28 (85\%) among 33, 19 (90\%) among 21, $16(84 \%)$ among 19, and $14(82 \%)$ among 17, respectively. Thirty patients $(77 \%)$ improved in their pretreatment symptoms, 2 (5\%) remained unchanged, and $7(18 \%)$ deteriorated during follow-up. For 20 patients (51\%), steroids either were never used or could be tapered off completely post-GKS. For 8 patients (21\%), the dose could be reduced to less than $4 \mathrm{mg}$, whereas 11 patients $(28 \%)$ had to continue or increase the dose to $4 \mathrm{mg}$ or more. Within the 12 months in which QOL was monitored, the peripheral disease progressed in 24 patients $(62 \%)$, and 22 patients $(56 \%)$ reported new symptoms unrelated to the BMs treated at baseline.

\section{Mean QOL}

The number of patients completing the FACT-BR at baseline and 1, 3, 6, 9, and 12 months after GKS were 43 (98\%) of $44,38(97 \%)$ of $39,28(85 \%)$ of $33,19(90 \%)$ of $21,16(84 \%)$ of 19 , and $14(82 \%)$ of 17 , respectively. Values for QOL dimensions for the above groups are compared with reference values for the general population in Table 2. An improved QOL (BRCS) was reported by $23(60.0 \%)$
TABLE 1. Baseline characteristics for 44 consecutive patients with BMs from LC treated with GKS in the period from May 2010 to September 2011 in Bergen, Norway

\begin{tabular}{lc}
\hline \multicolumn{1}{c}{ Variable } & Value \\
\hline Median age in yrs (range) & $62.8(42-82)$ \\
\hline Sex (no. [\%]) & \\
M & $25(56.8)$ \\
F & $19(43.2)$ \\
\hline Primary diagnosis (no. [\%]) & \\
NSCLC & $39(88.6)$ \\
SCLC & $5(11.4)$ \\
\hline Pretreatment symptoms from BMs (no. [\%]) & \\
Asymptomatic & $8(18.2)$ \\
Yes, but resolved on steroids & $18(40.9)$ \\
Yes & $18(40.9)$ \\
\hline Extracranial metastases at GKS (no. [\%]) & \\
None & $16(36.4)$ \\
Others & $4(9.1)$ \\
Liver & $3(6.8)$ \\
Bone & $6(13.6)$ \\
Adrenal & $9(20.5)$ \\
Lymph nodes & $12(27.3)$ \\
\hline Steroid medication at GKS (no. [\%]) & \\
Yes & $34(77.3)$ \\
No & $10(22.7)$ \\
\hline KPS score (no. [\%]) & \\
100 & $5(11.4)$ \\
90 & $14(31.8)$ \\
80 & $9(20.5)$ \\
70 & $10(22.7)$ \\
$<70$ & $6(13.6)$ \\
\hline RPA class (no. [\%]) & \\
1 & $12(27.3)$ \\
2 & $28(63.6)$ \\
3 & $4(9.1)$ \\
\hline Mean no. of BMs at 1st GKS (range) & $2.3(1-5)$ \\
\hline No. of BMs at 1st GKS (no. [\%]) & \\
1 & $15(34.1)$ \\
2 & $12(27.3)$ \\
3 & $8(18.2)$ \\
4 & $6(13.6)$ \\
5 & $5(6.8)$ \\
\hline Total BM vol (no. [\%]) & \\
$\leq 5 \mathrm{~cm}^{3}$ & $32(72.7)$ \\
$>5 \mathrm{~cm}^{3}$ & $12(27.3)$ \\
\hline Peritumoral edema (no. [\%]) & \\
$<20 \mathrm{~cm}^{3}$ & $31(70.5)$ \\
$>20 \mathrm{~cm}^{3}$ & $13(29.5)$ \\
\hline & \\
\hline & \\
\hline & \\
\hline
\end{tabular}

of the 39 patients surviving more than 1 month post-GKS, an unchanged QOL by 6 (15.4\%), and a reduced QOL by $9(23.1 \%)$. Our primary objective in this study was to determine whether GKS has an overall positive or negative impact on QOL. The MLM analysis showed that mean values for all QOL dimensions (PWB, SWB, EWB, FWB, FACT-G, BRCS, Total, and TOI) remained unchanged from baseline up to 12 months post-GKS. 

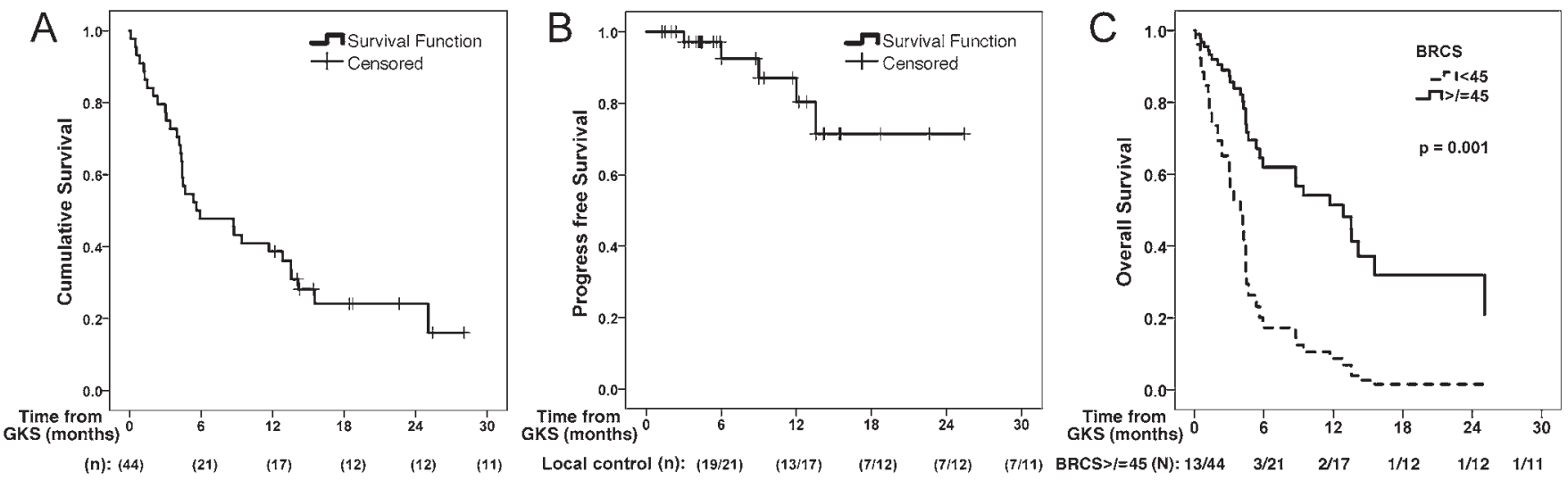

FIG. 1. A: Kaplan-Meier overall survival curve for 44 patients with primary LC treated for $102 \mathrm{BMs}$ using GKS at Haukeland University Hospital in Bergen, Norway, in the period from May 2010 to September 2011. $n=$ number of patients alive at each time point. B: Kaplan-Meier progression-free survival curve for 44 patients with primary LC treated using GKS. $n=$ number of patients with local control/number of patients alive. C: Cox regression survival analysis curves according to a baseline BRCS score $\geq 45$ versus $<45$ for 44 consecutive patients with BMs from LC who were treated with GKS. $n=$ number of patients with BRCS score $<$ $45 /$ number of patients alive.

\section{Part 1}

Baseline Predictors for Improved QOL Following GKS

Our secondary objective in this study was to identify, based on baseline characteristics, potential subgroups of patients that would either improve or decline in QOL as a result of GKS. The MLM analyses with time interaction were used to identify changes in QOL during followup. The resulting b-value (regression coefficient for time) is the size of the QOL improvement or deterioration per month of follow-up (slope of the QOL changes; Table 2).

Total BM volume at treatment was the only variable that significantly predicted the slope of the QOL curves (Table 3, Model 2a, time $\times$ total BM volume). The 32 patients (73\%) with tumors $\leq 5 \mathrm{~cm}^{3}$ improved by 0.45 BRCS points $(\mathrm{p}=0.04)$ for each month of follow-up, whereas the 12 patients with tumor volumes $>5 \mathrm{~cm}^{3}$ dropped 0.50 (BRCS) points each month (Fig. 2A). Tumor volumes $\leq$ $5 \mathrm{~cm}^{3}$ significantly more often completely responded to GKS than the tumors $>5 \mathrm{~cm}^{3}(p=0.02)$, although the local control rate did not differ significantly $(\mathrm{p}=0.15)$. The rate of pretreatment symptoms and symptomatic relief following GKS were similar for patients with tumors $>5 \mathrm{~cm}^{3}$ and $\leq 5 \mathrm{~cm}^{3}$. However, 17 of the 28 evaluable patients with small tumor volumes never used or were able to completely taper off steroids, 3 used low-dose steroids, and 8 used high-dose steroids, during follow-up. Similar numbers for the 11 evaluable patients with tumors $>5 \mathrm{~cm}^{3}$ were 3,5 , and 3 , respectively $\left(\mathrm{p}=0.04, \chi^{2}=6.4, \mathrm{df}=2\right)$. Moreover, only 15 of 28 patients with small BM volumes experienced extracranial disease progression during fol-

TABLE 2. Results of mixed linear regression analyses of QOL dimensions in 44 patients with BMs treated with GKS*

\begin{tabular}{|c|c|c|c|c|c|c|c|c|c|}
\hline \multirow[b]{2}{*}{ Factor } & \multirow{2}{*}{$\begin{array}{c}\text { General } \\
\text { Population† }\end{array}$} & \multicolumn{6}{|c|}{ Time Point (mos) } & \multirow[b]{2}{*}{ b-Valuef } & \multirow{2}{*}{$\begin{array}{c}p \\
\text { Value§ }\end{array}$} \\
\hline & & 0 & 1 & 3 & 6 & 9 & 12 & & \\
\hline Complianceף & & $43 / 44(98 \%)$ & $38 / 39(97 \%)$ & $28 / 33(85 \%)$ & $19 / 21(90 \%)$ & $16 / 19(84 \%)$ & $14 / 17(82 \%)$ & & \\
\hline \multicolumn{10}{|l|}{ QOL dimension } \\
\hline PWB score & $22.7(5.4)$ & $19.8(6.3)$ & $20.2(4.1)$ & $18.7(6.3)$ & $19.1(4.2)$ & $21.2(4.6)$ & $19.6(6.3)$ & -0.074 & 0.593 \\
\hline SWB score & $19.1(6.8)$ & $21.8(4.0)$ & $20.3(4.0)$ & $20.5(4.3)$ & $21.6(5.2)$ & $22.7(2.8)$ & $22.3(3.4)$ & -0.026 & 0.789 \\
\hline EWB score & $19.9(4.8)$ & $17.0(4.9)$ & $16.9(4.7)$ & $15.7(5.9)$ & $16.7(3.9)$ & $16.5(4.2)$ & $15.7(5.9)$ & -0.162 & 0.169 \\
\hline FWB score & $18.5(6.8)$ & $15.5(5.6)$ & $15.2(5.1)$ & $15.9(6.1)$ & $17.2(5.4)$ & $17.2(4.6)$ & $15.8(4.6)$ & -0.074 & 0.575 \\
\hline FACT-G score & 80.1 (18.1) & $74.1(15.6)$ & $72.7(13.0)$ & $71.4(16.6)$ & $76.6(14.6)$ & $77.8(11.9)$ & $73.4(16.5)$ & -0.400 & 0.257 \\
\hline BRCS score & & $53.0(11.5)$ & $55.0(11.2)$ & $52.8(12.9)$ & $56.4(7.4)$ & $57.0(7.9)$ & $57.1(10.4)$ & 0.121 & 0.624 \\
\hline Total score & & $127.1(24.8)$ & $127.7(22.3)$ & $124.8(28.4)$ & $133.0(19.5)$ & $134.5(18.7)$ & $130.5(25.4)$ & -0.367 & 0.496 \\
\hline TOI score & & $88.3(20.0)$ & $90.4(17.3)$ & $87.4(22.3)$ & $97.7(13.4)$ & $95.2(15.4)$ & $92.4(19.3)$ & -0.140 & 0.746 \\
\hline
\end{tabular}

BRCS = brain cancer subscale/additional concerns (score range 0-76); EWB = emotional well-being (0-24); FACT-G = PWB + SWB + EWB + FWB (0-108); FWB = functional well-being (0-28); PWB = physical well-being (0-28); SWB = social well-being (0-28); TOI = PWB + FWB + BRCS (0-132); Total = FACT-G + BRCS (0-184).

* Assuming a first-order autoregressive correlation structure; values expressed as the mean (SD), unless indicated otherwise.

† Reference means (SDs) for the general population. Brucker PS, Yost K, Cashy J, Webster K, Cella D: General population and cancer patient norms for the Functional

Assessment of Cancer Therapy-General (FACT-G). Eval Health Prof 28:192-211, 2005.

‡ Regression coefficient for time, or size of QOL improvement or deterioration per month of follow-up.

$\S$ Calculated from F-test for time, adjusted for age and sex.

If Number of responders/number alive (\%). 
TABLE 3. Baseline predictors for QOL among 44 patients with BMs treated with GKS*

\begin{tabular}{|c|c|c|c|c|}
\hline \multirow[b]{2}{*}{ Explanatory Variables $†$} & \multicolumn{4}{|c|}{ QOL Dimension } \\
\hline & FACT-G & BRCS & Total & TOI \\
\hline \multicolumn{5}{|l|}{ Model 1} \\
\hline \multicolumn{5}{|l|}{ Age in yrs } \\
\hline b & -0.3 & -0.2 & -0.5 & -0.3 \\
\hline $95 \% \mathrm{Cl}$ & $-0.8,0.1$ & $-0.5,0.2$ & $-1.2,0.2$ & $-0.9,0.2$ \\
\hline$p$ value & 0.138 & 0.338 & 0.172 & 0.239 \\
\hline \multicolumn{5}{|l|}{ Sex, M vs F } \\
\hline b & -2.4 & 3.6 & 1.6 & 2.0 \\
\hline $95 \% \mathrm{Cl}$ & $-10.5,5.7$ & $-2.2,9.5$ & $-11.8,14.9$ & $-8.6,12.5$ \\
\hline$p$ value & 0.558 & 0.219 & 0.815 & 0.706 \\
\hline \multicolumn{5}{|l|}{ Time since GKS in mos } \\
\hline b & -0.4 & 0.1 & -0.4 & -0.1 \\
\hline $95 \% \mathrm{Cl}$ & $-1.1,0.3$ & $-0.4,0.6$ & $-1.4,0.7$ & $-1.0,0.7$ \\
\hline$p$ value & 0.256 & 0.621 & 0.493 & 0.749 \\
\hline \multicolumn{5}{|l|}{ Model 2a } \\
\hline \multicolumn{5}{|l|}{ Total tumor vol, $\leq 5$ vs $>5 \mathrm{~cm}^{3}$} \\
\hline b & 4.1 & & 5.9 & \\
\hline $95 \% \mathrm{Cl}$ & $-4.8,13.0$ & & $-8.8,20.7$ & \\
\hline$p$ value & 0.360 & 0.621 & 0.420 & 0.192 \\
\hline \multirow{2}{*}{\multicolumn{5}{|c|}{$\begin{array}{l}\text { Time } \times \text { total tumor vol } \\
\leq 5 \mathrm{~cm}^{3}\end{array}$}} \\
\hline & & & & \\
\hline b & & 0.45 & & 0.4 \\
\hline $95 \% \mathrm{Cl}$ & & $-0.1,1.0$ & & $-0.6,1.4$ \\
\hline \multicolumn{5}{|l|}{$>5 \mathrm{~cm}^{3}$} \\
\hline $\mathrm{b}$ & & -0.50 & & -1.2 \\
\hline $95 \% \mathrm{Cl}$ & & $-1.3,0.3$ & & $-2.5,0.16$ \\
\hline $\mathrm{p}$ value & 0.590 & 0.041 & 0.216 & 0.048 \\
\hline \multicolumn{5}{|l|}{ Model 2b } \\
\hline \multicolumn{5}{|c|}{ Symptomatic BM at GKS } \\
\hline \multicolumn{5}{|c|}{ Yes, but resolved on steroids vs asymptomatic } \\
\hline b & -4.7 & -5.0 & -9.9 & -10.6 \\
\hline $95 \% \mathrm{Cl}$ & $-15.6,6.2$ & $-12.5,2.6$ & $-27.4,7.6$ & $-24.1,-2.8$ \\
\hline \multicolumn{5}{|l|}{ Yes vs asymptomatic } \\
\hline b & -11.8 & -11.2 & -23.5 & -20.9 \\
\hline $95 \% \mathrm{Cl}$ & $-22.9,-0.8$ & $-18.8,-3.5$ & $-41.2,-5.74$ & $-34.5,-7.2$ \\
\hline$p$ value & 0.078 & 0.013 & 0.025 & 0.011 \\
\hline \multicolumn{5}{|l|}{ Model 2c } \\
\hline \multicolumn{5}{|l|}{ KPS score (0-100) } \\
\hline b & 3.7 & 3.8 & 7.5 & 7.2 \\
\hline $95 \% \mathrm{Cl}$ & $0.34,7.04$ & $1.49,6.00$ & $2.16,12.8$ & $3.22,11.2$ \\
\hline$p$ value & 0.032 & 0.002 & 0.007 & 0.001 \\
\hline \multicolumn{5}{|l|}{ Model 2d } \\
\hline \multicolumn{5}{|l|}{ RPA } \\
\hline \multicolumn{5}{|l|}{ Class 1 vs Class 3} \\
\hline $\mathrm{b}$ & 14.7 & 14.4 & 28.6 & 26.2 \\
\hline $95 \% \mathrm{Cl}$ & $-1.90,31.2$ & $2.88,25.8$ & $1.83,55.3$ & $5.59,46.8$ \\
\hline \multicolumn{5}{|l|}{ Class 2 vs Class 3} \\
\hline b & 10.7 & 12.5 & 23.2 & 19.9 \\
\hline $95 \% \mathrm{Cl}$ & $-4.02,25.4$ & $2.3,22.7$ & $-0.53,50.0$ & $1.54,38.2$ \\
\hline $\mathrm{p}$ value & 0.215 & 0.043 & 0.105 & 0.47 \\
\hline
\end{tabular}

Boldface type indicates statistical significance.

* Results from mixed linear regression analyses of each QOL scale of the FACT-BR. Model 1: Estimates from model with only the main effects of age, sex, and time. Models 2a-d: Adding 1 variable at a time to the variables in Model 1 and testing the interaction of this with time. For models with a significant interaction with time, the subclass-specific regression coefficients for time are provided. For all models, a first-order autoregressive correlation structure was assumed.

$\dagger$ The $p$ value was calculated from the $F$ test for time, adjusted for age and sex. The $b$-value was the regression coefficient for time. 

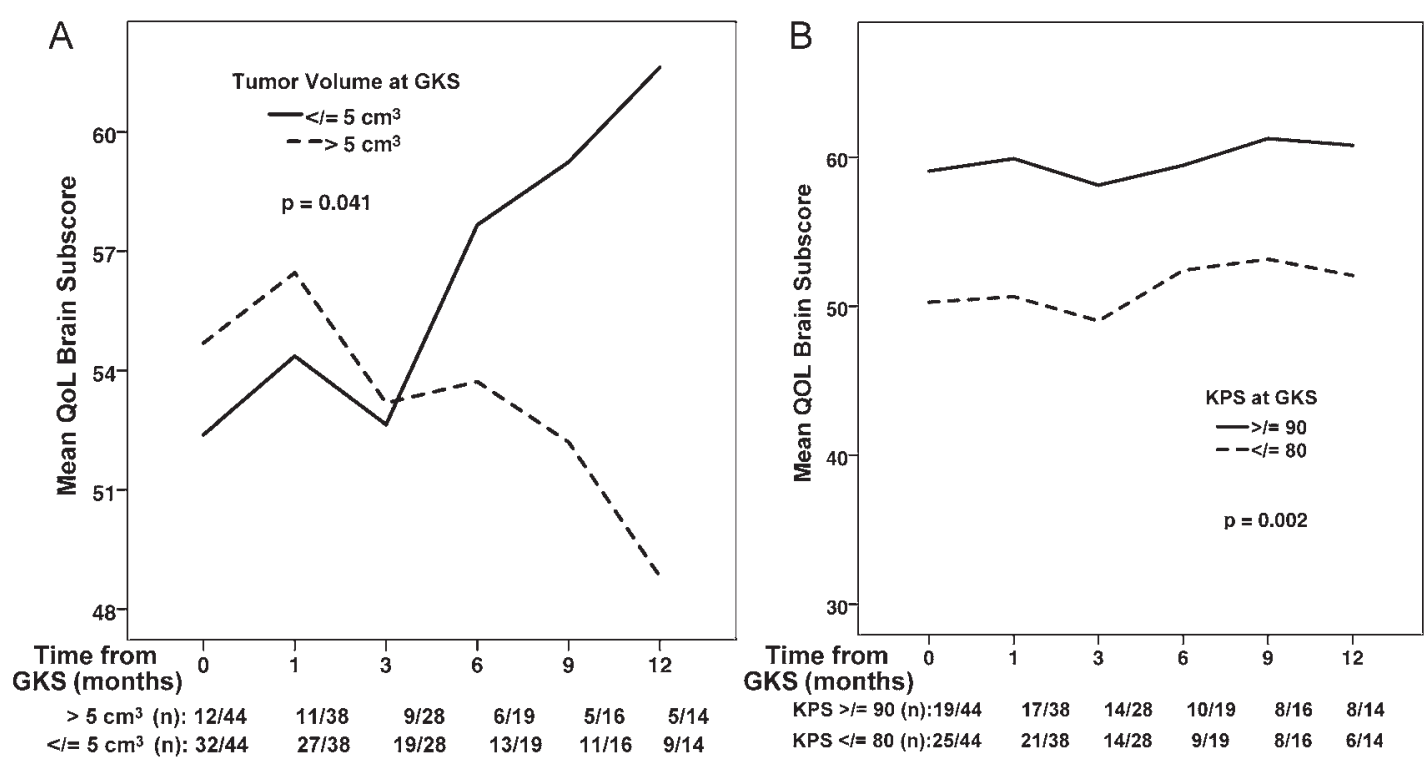

FIG. 2. A: Curves for the BRCS illustrating changes in QOL according to total BM volume $\leq 5 \mathrm{~cm}^{3}$ versus $>5 \mathrm{~cm}^{3}$. Quality of life was evaluated at baseline and 1, 3, 6, 9, and 12 months post-GKS. B: Curves for the BRCS according to a baseline KPS score $\geq$ 90 versus $\leq 80$ for 44 LC patients after treatment with GKS. Patient-reported QOL was registered at baseline and 1, 3, 6, 9, and 12 months after GKS.

low-up compared to 9 of 11 patients with BM volumes $>5$ $\mathrm{cm}^{3}\left(\mathrm{p}=0.03, \chi^{2}=4.6, \mathrm{df}=1\right)$.

\section{Baseline Predictors for High and Stable QOL Following GKS}

All examined baseline predictors except for tumor volume demonstrated stable mean QOL values following GKS, signifying a nonsignificant time interaction. However, some parameters predicted a significant difference in QOL for subgroups of patients, although the observed changes in QOL remained constant with QOL curves maintaining a parallel pattern throughout followup. Similarly, the difference in mean QOL remained stable at all evaluation points. The b-values define the size of the difference in mean QOL between the patient subgroups calculated in the MLM analyses without time interaction (Table 3, Model 2a: total BM volume and Models 2b, 2c, and $2 \mathrm{~d}$ ).

Asymptomatic BMs at baseline predicted high and stable QOL after treatment (BRCS: $p=0.01$, Total: $p=0.03$ ). Patients with asymptomatic lesions had BRCS scores 11.2 points higher and Total scores 23.5 points higher than the patients with symptomatic BMs at any time point. However, if patient symptoms due to BMs had regressed on steroid treatment before GKS, the BRCS scores were 5.0 and the Total scores were 9.9 points lower than those for patients with true asymptomatic lesions (Table 3, Model 2b).

The KPS score at baseline was a strong predictor for a high and stable QOL after GKS (BRCS: $\mathrm{p}<0.01$, Total: $\mathrm{p}$ $<0.01)$. For every 10 points on the KPS, patients had QOL scores with an additional 3.8 (BRCS) and 7.5 points (Total; Fig. 2B and Table 3, Model 2c).

Patients with a lower RPA class had higher BRCS scores $(\mathrm{p}=0.04)$. The RPA Class 1 and 2 patients had BRCS scores 14.4 and 12.5 points higher than the scores in the RPA Class 3 patients at all evaluation time points (Table 3, Model 2d).
Notably, age, sex, number of BMs, prior treatment, SRS integral dose to the cranium, extent of peritumoral edema, mutation status, baseline metastases to bone, liver, adrenal glands, or lymph nodes at GKS did not predict QOL in terms of BRCS or Total scores.

\section{Multivariate Analyses}

After backward stepwise regression analysis of all predictive factors, KPS score remained the only significant predictor for both the BRCS $(\mathrm{p}<0.01)$ and the Total score $(\mathrm{p}=0.01)$ with a corresponding increase in QOL of 3.0 and 7.5 points, respectively, for every 10-point increase in the KPS score.

\section{Effect of Treatment and Disease Progression on QOL During Follow-Up}

None of the follow-up variables-local failure, distant cerebral failure, retreatments with GKS, cumulative integral dose to the cranium, RTOG complications, changes in cerebral symptoms, targeted therapy, or extracranial disease progression-significantly impacted QOL as measured by the BRCS or Total score.

\section{Part 2}

\section{Predictors for Survival in Unadjusted Models}

In univariate analyses (unadjusted Cox models), QOL as measured by the BRCS at baseline was a significant predictor of survival (Table 4). The higher the BRCS score at baseline, the longer the patient survival. Patients with baseline BRCS scores $<45$ had a median survival of 3.4 months (95\% CI 0.27-6.53) and an HR of 2.52 for death $(95 \%$ CI $1.22-5.2, p=0.01)$ versus patients with BRCS scores $\geq 45$, who had a median survival of 9.4 months (95\% CI 3.4-15.4, $\mathrm{p}=0.01)$.

Moreover, the HR for death for males was 2.64 ( $\mathrm{p}=$ 
TABLE 4. Results of Cox proportional-hazards regression analysis of survival for 44 patients with BMs treated with GKS, with follow-up until September 2012

\begin{tabular}{|c|c|c|c|c|c|c|c|c|c|}
\hline \multirow[b]{2}{*}{ Variable: Categories } & \multicolumn{3}{|c|}{ Unadjusted } & \multicolumn{3}{|c|}{ Adjusted* } & \multicolumn{3}{|c|}{ Final Model† } \\
\hline & $\mathrm{HR}$ & $95 \% \mathrm{Cl}$ & $p$ Value & $\mathrm{HR}$ & $95 \% \mathrm{Cl}$ & $p$ Value & $\mathrm{HR}$ & $95 \% \mathrm{Cl}$ & $\mathrm{p}$ Value \\
\hline Sex: M vs F & 2.64 & $1.23,5.65$ & 0.012 & 3.15 & $1.23,8.08$ & 0.017 & 3.05 & $1.35,6.87$ & 0.007 \\
\hline Age in yrs: $\geq 65$ vs $<65$ & 1.41 & $0.68,2.91$ & 0.351 & & & & & & \\
\hline PWB score: <14 vs >21 & 1.30 & $0.49,3.44$ & 0.684 & & & & & & \\
\hline PWB score: $14-21$ vs >21 & 1.40 & $0.64,3.04$ & & & & & & & \\
\hline SWB score: $<21$ vs $\geq 21$ & 1.76 & $0.86,3.58$ & 0.121 & & & & & & \\
\hline EWB score: $<12$ vs $>18$ & 0.87 & $0.32,2.38$ & 0.850 & & & & & & \\
\hline EWB score: $12-18$ vs $>18$ & 1.18 & $0.53,2.61$ & & & & & & & \\
\hline FWB score: $14-21$ vs >21 & 1.27 & $0.44,3.64$ & 0.455 & & & & & & \\
\hline FWB score: $<14$ vs $>21$ & 1.81 & $0.64,5.10$ & & & & & & & \\
\hline FACT-G score: $<72$ vs $\geq 72$ & 0.94 & $0.46,1.92$ & 0.857 & & & & & & \\
\hline BRCS score: $<45$ vs $\geq 45$ & 2.52 & $1.22,5.20$ & 0.013 & 3.12 & $1.20,8.13$ & 0.020 & 3.67 & $1.68,8.03$ & 0.001 \\
\hline Total score: $115-138$ vs >161 & 2.05 & $0.43,9.83$ & 0.062 & & & & & & \\
\hline Total score: $<115$ vs $>161$ & 4.50 & $0.99,20.52$ & & & & & & & \\
\hline Total score: $138-161$ vs $>161$ & 4.97 & $1.02,24.08$ & & & & & & & \\
\hline TOI score: $<80$ vs $>80$ & 1.75 & $0.86,3.55$ & 0.121 & & & & & & \\
\hline Primary diagnosis: NSCLC vs SCLC & 1.22 & $0.47,3.18$ & 0.687 & & & & & & \\
\hline EGFR mutation: positive vs negative & 0.22 & $0.03,1.80$ & 0.158 & & & & & & \\
\hline Targeted therapy vs nontargeted therapy & 0.17 & $0.02,1.39$ & 0.096 & & & & & & \\
\hline KPS score: $\leq 70$ vs $>70$ & 2.42 & $1.19,4.91$ & 0.014 & 1.48 & $0.60,3.65$ & 0.393 & & & \\
\hline RPA class: 3 vs 1 & 0.49 & $0.16,1.45$ & 0.202 & & & & & & \\
\hline RPA class: 2 vs 1 & 0.33 & $0.97,1.11$ & 0.074 & & & & & & \\
\hline No. of BMs: 3 vs 1 & 1.30 & $0.44,3.82$ & 0.629 & & & & & & \\
\hline No. of BMs: 2 vs 1 & 1.99 & $0.69,5.70$ & 0.200 & & & & & & \\
\hline No. of BMs: 3 vs 1 & 1.20 & $0.36,3.96$ & 0.761 & & & & & & \\
\hline BM localization: cerebellum/brainstem vs not & 1.01 & $0.51,2.00$ & 0.975 & & & & & & \\
\hline Extracranial metastases at GKS: yes vs no & 0.61 & $0.29,1.28$ & 0.186 & & & & & & \\
\hline Liver metastases at GKS: yes vs no & 4.49 & $1.25,16.19$ & 0.022 & 0.99 & $0.22,4.45$ & 0.992 & & & \\
\hline Bone metastases at GKS: yes vs no & 2.83 & $1.14,7.20$ & 0.025 & 3.40 & $0.66,8.76$ & 0.186 & 3.02 & $1.17,7.83$ & 0.023 \\
\hline Adrenal metastases at GKS: yes vs no & 2.64 & $1.19,5.85$ & 0.017 & 0.99 & $0.33,2.97$ & 0.990 & & & \\
\hline Lymph node metastases at GKS: yes vs no & 0.44 & $0.19,1.02$ & 0.055 & & & & & & \\
\hline
\end{tabular}

Boldface type indicates statistical significance.

* First step of adjusted model including all variables with $p \leq 0.05$ in the unadjusted analyses.

$\dagger$ Remaining variables at $p \leq 0.5$ after backward stepwise selection from the adjusted model.

$0.01)$, with a median survival of 4.4 months $(95 \%$ CI $4.2-$ 4.7) for men compared with 14.2 months ( $95 \%$ CI 3.0 to 25.4, $\mathrm{p}=0.01$ ) for women.

Patients with baseline KPS scores $\leq 70$ (vs $>70$ ) were found to have an HR of 2.42 for death $(p=0.01)$ and a median survival of 3.0 (95\% CI $0.26-5.74)$ versus 9.4 months (95\% CI 3.62-15.2), respectively.

Furthermore, baseline metastasis to liver, bone, and adrenal gland were associated with shorter survival. If a patient had liver metastases at GKS, the HR for death was $4.49(\mathrm{p}=0.02)$ with a median survival of 2.4 months $(95 \%$ CI $0.98-3.75)$ versus 8.7 months (95\% CI 3.7-13. 8; $\mathrm{p}=$ 0.01 ) in patients without such metastases. Similarly, bone metastases at GKS predicted a poor median survival of 2.0 months (95\% CI $0.96-3.04$ ) versus 5.9 months (95\% CI $0.77-11.0 ; p=0.02$ ) in those without, with an HR of 2.83 $(\mathrm{p}=0.03)$. Finally, baseline metastasis to the adrenal gland was a significant negative predictor for survival (HR 2.64, $\mathrm{p}=0.02$ ). Median survival for patients with adrenal gland metastases was 4.2 months (95\% CI $0.95-7.4$ ) versus 8.8 months (95\% CI 1.7-15.8; $\mathrm{p}=0.01)$ for patients without.

Actuarial 3- and 6-month survival rates for patients with BRCS scores $\geq 45$ were $83.3 \%$ and $56.7 \%$ versus $53.8 \%$ and $15.4 \%$, respectively, for patients with baseline BRCS scores $<45(\mathrm{p}=0.01)$. For females, the actuarial 3and 6-month survival rates were $78.9 \%$ and $68.4 \%$ versus $72.0 \%$ and $24.0 \%$, respectively, for males $(\mathrm{p}=0.01)$. $\mathrm{Pa}-$ tients with bone metastases at baseline had 3-and 6-month actuarial survival rates of $16.7 \%$ and $16.7 \%$ versus $84.2 \%$ and $47.4 \%$, respectively, if patients had no baseline bone metastases $(\mathrm{p}=0.02)$.

Notably, age, primary diagnosis (SCLC/NSCLC), 
TABLE 5. Results of Cox proportional-hazards regression analysis of survival in 44 patients with BMs treated with GKS, comparing BRCS, GPA score, RPA class, and SIR

\begin{tabular}{|c|c|c|c|c|c|c|c|c|c|c|c|}
\hline \multirow[b]{2}{*}{ Variable } & \multirow[b]{2}{*}{ Category } & \multirow{2}{*}{$\begin{array}{c}\text { No. of } \\
\text { Patients }\end{array}$} & \multicolumn{3}{|c|}{ Unadjusted } & \multicolumn{3}{|c|}{ Adjusted } & \multicolumn{3}{|c|}{ Final Model } \\
\hline & & & $\mathrm{HR}$ & $95 \% \mathrm{Cl}$ & $p$ Value & $\mathrm{HR}$ & $95 \% \mathrm{Cl}$ & p Value & $\mathrm{HR}$ & $95 \% \mathrm{Cl}$ & $p$ Value \\
\hline \multirow[t]{2}{*}{ BRCS score } & $<45$ & 13 & 2.52 & $1.22,5.20$ & 0.013 & 2.37 & $0.99,5.67$ & 0.059 & 2.52 & $1.22,5.20$ & 0.013 \\
\hline & $\geq 45$ & 30 & 1.00 & Reference & & 1.00 & Reference & & 1.00 & Reference & \\
\hline DS-GPA score & $0.5-4$ & 43 & 0.63 & $0.40,0.99$ & 0.047 & 0.61 & $0.25,1.47$ & 0.265 & & & \\
\hline \multirow[t]{3}{*}{ RPA class } & 1 & 4 & 1.00 & Reference & 0.202 & 1.00 & Reference & 0.910 & & & \\
\hline & 2 & 27 & 1.48 & $0.65,3.36$ & 0.353 & 1.09 & $0.31,3.80$ & & & & \\
\hline & 3 & 12 & 3.04 & $0.90,10.3$ & 0.074 & 1.46 & $0.21,10.1$ & & & & \\
\hline \multirow[t]{3}{*}{ SIR score } & $1-3$ & 3 & 1.00 & Reference & 0.843 & 1.00 & Reference & 0.546 & & & \\
\hline & $4-7$ & 37 & 1.44 & $0.337,6.14$ & 0.623 & 1.97 & $0.39,9.95$ & & & & \\
\hline & $8-10$ & 3 & 1.12 & $0.15,8.14$ & 0.913 & 3.01 & $0.34,26.6$ & & & & \\
\hline
\end{tabular}

Boldface type indicates statistical significance. The $p$ values were calculated from the likelihood ratio test.

EGFR mutation status, targeted therapy, number of BMs, BM location, RPA class, absence of extracranial metastases, and baseline metastases to lymph nodes did not predict survival (Tables 4 and 5).

\section{Predictors for Survival in Adjusted Models}

In the first step of the adjusted Cox regression analysis (Table 4) including all significant factors from the univariate analyses, only female versus male sex $(p=0.02)$ and BRCS score $\geq 45$ versus $<45(p=0.02)$ remained significant predictors for longer survival.

In the final step of the adjusted model (Table 4), a BRCS score $\geq 45$ ( $p<0.01$; Fig. 1C), female sex $(p<0.01)$, and the absence of bone metastases at GKS $(p=0.02)$ were significantly related to longer survival. Patients with a BRCS score $<45$ had an HR of 3.67 for death, compared to patients with a BRCS score $\geq 45$. Males had an HR of 3.05 for death compared to females, and patients with bone metastases had an HR of 3.02 for death compared to patients without bone metastases.

Finally, we compared the predictive values for survival in a Cox proportional-hazards regression model between BRCS score, RPA class, DS-GPA score, and SIR (Table 5). Both the BRCS $(p=0.01)$ and DS-GPA $(p=0.05)$ scores were significant unadjusted predictors. Although none of the indices were significant in the adjusted analysis, a higher BRCS score still showed a positive effect of 2.37 and a trend toward improved survival $(p=0.06)$. Furthermore, BRCS score remained significant in the final model with an HR of 2.52 (95\% CI 1.22-5.20, $\mathrm{p}=0.01)$.

We then compared the predictive value of the BRCS with the values for the variables behind RPA, DS-GPA, and SIR: age, KPS score, BM number, BM volume, and extracranial disease status. Both higher BRCS scores and higher KPS scores were significantly associated with longer survival when no other variables were adjusted for. In the adjusted model, BRCS $(\mathrm{p}=0.06)$ and BM volume $(\mathrm{p}$ $=0.08$ ) showed a trend toward significance. The HR for a BRCS score $\geq 45$ versus $<45$ was still high (2.54), showing a positive effect on survival. In the final model, BRCS score $(\mathrm{p}=0.01)$ and $\mathrm{BM}$ volume $(\mathrm{p}=0.04)$ remained significant predictors for survival (Table 6).

\section{Discussion}

\section{Quality of Life Following Gamma Knife Treatment}

Quality of life is a direct measurement of the clinical benefit of treatment from the patient perspective, integrating the effects of both treatment-related toxicity and disease progression. ${ }^{24}$ The purpose of QOL questionnaires validated for use in $\mathrm{BM}$ patients is to reflect the cerebral part of the disease. However, QOL may depend on the site of the primary cancer in the same way that survival depends on the primary cancer site, ${ }^{33}$ and volumetric response after GKS varies by cell of origin. ${ }^{19}$ Our results show that $77 \%$ of the LC patients improved and $82 \%$ had stable or improved cerebral symptoms at the last followup. Moreover, $60 \%$ reported improved and $75 \%$ reported stable or improved QOL after GKS, using the BRCS. In line with the present study, 3 prospective nonrandomized studies investigating QOL after SRS alone ${ }^{16,25,30}$ for BMs from mixed primaries have shown that the SRS itself does not reduce QOL. In fact, QOL improved or remained unchanged in $60 \%-70 \%$ of the patients in those studies, reflecting the high efficacy and low complication rate associated with SRS.

\section{Limited Intracranial Tumor Volume and Improved QOL Following GKS}

For LC patients, the cerebral part of the disease seems particularly important as the size of the lesion predicts QOL improvement or deterioration. Lung cancer patients with a total $\mathrm{BM}$ volume $\leq 5 \mathrm{~cm}^{3}$ improved significantly in their QOL up to 12 months after GKS, whereas the patients with larger BMs, seen in only $27 \%$ of the patients, reported reduced QOL. Although the presence of baseline symptoms, the rate of symptomatic relief following GKS, and the overall local control rates were the same in these 2 patient groups, we found a significantly higher complete versus partial response rate for the smaller tumors. Furthermore, patients with small tumors were less often started on steroids and could more often be completely tapered off the steroids after treatment, possibly because of the small tumor size and the high rate of complete response at follow-up. Finally, we found a significantly higher rate 
TABLE 6. Results of Cox proportional-hazards regression analysis of survival in 44 patients with BMs treated with GKS, comparing BRCS with the variables that make up RPA, DS-GPA, and SIR

\begin{tabular}{|c|c|c|c|c|c|c|c|c|c|c|c|}
\hline \multirow[b]{2}{*}{ Variable } & \multirow[b]{2}{*}{ Category } & \multirow{2}{*}{$\begin{array}{c}\text { No. of } \\
\text { Patients }\end{array}$} & \multicolumn{3}{|c|}{ Unadjusted } & \multicolumn{3}{|c|}{ Adjusted } & \multicolumn{3}{|c|}{ Final Model } \\
\hline & & & $\mathrm{HR}$ & $95 \% \mathrm{Cl}$ & $p$ Value & $\mathrm{HR}$ & $95 \% \mathrm{Cl}$ & $p$ Value & $\mathrm{HR}$ & $95 \% \mathrm{Cl}$ & $\mathrm{p}$ Value \\
\hline \multirow[t]{2}{*}{ BRCS } & $<45$ & 13 & 2.52 & $1.22,5.20$ & & 2.54 & $0.96,6.71$ & & 3.07 & $1.43,6.58$ & \\
\hline & $\geq 45$ & 30 & 1.00 & Reference & 0.013 & 1.00 & Reference & 0.063 & 1.00 & Reference & 0.006 \\
\hline KPS score & $0-100$ & 43 & 0.66 & $0.48,0.91$ & 0.011 & 0.55 & $0.27,1.12$ & 0.101 & & & \\
\hline \multirow[t]{3}{*}{ Age in yrs } & $>60$ & 30 & 2.00 & $0.47,8.52$ & & 1.54 & $0.33,7.17$ & & & & \\
\hline & $50-59$ & 9 & 1.51 & $0.32,7.13$ & & 2.16 & $0.39,12.1$ & & & & \\
\hline & $<50$ & 4 & 1.00 & Reference & 0.525 & 1.00 & Reference & 0.653 & & & \\
\hline \multirow[t]{3}{*}{ BM no. } & $>3$ & 9 & 0.77 & $0.26,2.25$ & & 1.61 & $0.48,5.37$ & & & & \\
\hline & $2-3$ & 19 & 1.25 & $0.57,2.72$ & & 1.76 & $0.52,5.92$ & & & & \\
\hline & 1 & 15 & 1.00 & Reference & 0.586 & 1.00 & Reference & 0.627 & & & \\
\hline \multirow[t]{3}{*}{$\mathrm{BM}$ vol in $\mathrm{cm}^{3}$} & $>13$ & 4 & 2.21 & $0.76,6.45$ & & 2.69 & $0.74,9.77$ & & 3.19 & $1.05,9.76$ & \\
\hline & $5-13$ & 7 & 0.49 & $0.17,1.43$ & & 0.33 & $0.08,1.43$ & & 0.46 & $0.15,1.36$ & \\
\hline & $<5$ & 32 & 1.00 & Reference & 0.118 & 1.00 & Reference & 0.081 & 1.00 & Reference & 0.045 \\
\hline \multirow{2}{*}{$\begin{array}{l}\text { Extracranial } \\
\text { metastases }\end{array}$} & Yes & 28 & 1.65 & $0.78,3.49$ & & 1.12 & $0.43,2.96$ & & & & \\
\hline & No & 16 & 1.00 & Reference & 0.174 & 1.00 & Reference & 0.815 & & & \\
\hline
\end{tabular}

Boldface type indicates statistical significance. The $p$ values were calculated from the likelihood ratio test.

of peripheral disease progression in the group with large tumor volumes. The additive effects of these differences may explain the opposite QOL slopes observed in these 2 patient groups. Habets et al. ${ }^{16}$ also demonstrated that large $\mathrm{BM}$ volumes were associated with a worse QOL after SRS in a cohort of patients with mixed primaries. Notably, large tumors were treated with fractionated SRS in that study. Moreover, Miller et al. found that QOL improved more if patients had solitary BMs rather than if they had more than $3 \mathrm{BMs},{ }^{25}$ also demonstrating an effect of the BM burden on QOL. Although we did not find statistical significance between integral dose and QOL, the phenomenon of leukoencephalopathy described after a high cumulative SRS integral dose to the cranium ${ }^{37}$ may explain the QOL deterioration seen in patients with large tumor volumes following GKS.

\section{Careful Follow-Up and Salvage GKS at Intracranial Progression}

Quality of life was unaffected by treatment failure after GKS. The reason may be that local failures and new distant lesions were detected on routine MRI follow-up before they became symptomatic and were retreated. However, this finding runs counter to the results published by Habets et al. ${ }^{16}$ and Aoyama et al. ${ }^{1}$ This difference may be explained by tumors that were larger and the less common use of salvage SRS in the Habets study compared with other studies. ${ }^{25,30}$ Of the 47 patients $(52 \%)$ with intracranial progression among the 90 who were evaluable, only 7 (15\%) underwent SRS and 13 (28\%) underwent WBRT. In comparison, $22(56 \%)$ of 39 evaluable patients in the present study had new lesions detected at follow-up, 15 of whom (68\%) were retreated with 1-3 subsequent GKS sessions and $4(18 \%)$ with WBRT. Aoyama et al. ${ }^{1}$ concluded that local and distant brain tumor control is the most important factor for stabilizing neurocognitive function given that patients treated with SRS+WBRT were found to be cognitively intact longer than the patients treated with SRS alone $(p=0.05)$. Cognitive deterioration was attributed to brain tumor recurrence in 3 and 11 patients in the SRS+WBRT group and the SRS group, respectively $(\mathrm{p}<$ $0.0001)$. The $\mathrm{BM}$ volumes $\left(<3 \mathrm{~cm}^{3}\right.$ in $45 \%-49 \%$ and $\geq 3$ $\mathrm{cm}^{3}$ in $51 \%-55 \%$ ) seem to be comparable with those in the present study $\left(<3 \mathrm{~cm}^{3}\right.$ in $48 \%$ and $\geq 3 \mathrm{~cm}^{3}$ in $52 \%$ of the patients), but the use of salvage therapy seems to be lower, although the exact number of retreatments for local and distant failures were not reported. Accordingly, a prospective study of up-front SRS has shown that WBRT can be avoided in approximately $70 \%$ of patients by using salvage repeat SRS when appropriate. ${ }^{9}$

\section{Effect of Peripheral Disease Progression on QOL and Survival}

The observation that QOL for LC patients was similar at follow-up regardless of whether peripheral disease had progressed or remained stable was surprising. Extracranial disease progression was significantly correlated with a worse QOL in an earlier study in which we enrolled patients with brain metastases from multiple primary sites. ${ }^{30}$ We know that the mean time from primary diagnosis to GKS was significantly shorter for the LC patients than for the mixed population (7.0 vs 22.9 months), the median survival was shorter (5.6 vs 7.5 months), and the neurological death rate was lower (7\% vs 22\%). Perhaps LC patients have a higher risk for a more sudden death at progression because of the vital function of the lungs and the proximity of the tumors to other vital organs (heart, large vessels, and esophagus). Therefore, QOL reduction may not be captured by routine follow-up. Alternatively, the location of the primary tumor may cause severe symptoms that more strongly impact on QOL during these patients' relatively short lifespans, regardless of whether these symptoms are controlled by treatment or not.

Extracranial metastases to liver, bone, and adrenal 
gland at baseline were significantly associated with a shorter survival. After multivariate analysis, metastases to bone remained the most significant distant site associated with poor survival. Bone metastasis occurs in 30\%-65\% of LC patients ${ }^{28}$ and is an advanced stage of the disease. Although patients with bone metastases can experience pain, pathological fractures, and immobility, they did not have a reduced QOL in the present study. We also identified patient sex as a strong predictor of survival, which is in line with findings in previous studies. ${ }^{2}$ Similar results were found in a study of patients with NSCLC, ${ }^{22}$ and it has been suggested that inequalities in tumor biology explain the difference in survival between males and females. ${ }^{40}$

\section{Quality of Life as a Predictor of Survival in LC Patients}

Data in the present study demonstrate that QOL the day before GKS, according to the BRCS, significantly predicted survival in both the univariate and the final step of the multivariate analyses. This finding is in line with results in a prior study in a cohort of 42 patients with advanced LC, in which baseline QOL as measured by the FACT-G significantly predicted survival. ${ }^{12}$ Braun et al. also studied the relationship between QOL, as measured by the EORTC Core Quality of Life Questionnaire, and survival in patients treated for NSCLC and found that baseline physical function and global QOL predicted survival. ${ }^{4}$ We believe this finding may be generalizable to patients with other primary cancers. Baseline QOL according to the Spitzer Quality of Life Index, a combination of physician report and patient self-report, was predictive of survival in a study evaluating QOL in BM patients with mixed primary tumors undergoing WBRT with and without thalidomide. ${ }^{11}$ Patient-reported information has been established as a predictor of mortality, as reported in a review by Idler et al. ${ }^{18}$ Accurate assessment of self-rated QOL has garnered growing interest as a routine tool in clinical studies for use in patients with cancer. ${ }^{29}$

\section{Physician-Rated Scales Versus Self-Reports of Patient Health as Prognostic Tools}

The BRCS of the QOL questionnaire was a strong predictor of survival as compared with the well-known prognostic indices of RPA, DS-GPA, and SIR. The BRCS score and BM volume were the most important subfactors highlighting the importance of the cerebral part of the disease. This observation is supported by a recent study by Cho et al., ${ }^{10}$ who concluded that the combined impact of the number of lesions and the cumulative tumor volume is a more significant prognostic factor than tumor volume or tumor number alone after GKS for BMs derived from NSCLC. In the present study, KPS score was a significant predictor of survival in the unadjusted analysis only and did not remain significant in the final step of the multivariate analysis. This result is in accordance with a recent finding that evaluations made by health care personnel are poorer than those self-reported by patients..$^{21}$

\section{Study Strengths and Limitations}

The strength of this study is the prospective design and high compliance rate. All patients were recruited from the neurosurgical department of the university hospital in Bergen, which has a national platform for GKS. The patients, although they could have different symptoms, made up a homogeneous and well-characterized group, all having metastases from LC. In addition, we used a validated and reliable questionnaire for BMs. ${ }^{23}$ The FACT-BR is longer and more comprehensive than general QOL questionnaires such as the SF-36 (36-Item Short Form Health Survey) and EuroQol with the risk of a reduced compliance rate but is more sensitive to important aspects of the general cancer disease $^{24}$ as well as potential symptoms due to BM or BM treatment.

The main limitation of this study is the small number of patients. Thus, the lack of significance in the results may be a reflection of underpowered analyses. Furthermore, multiple GKS treatments and the inclusion of patients with prior WBRT or surgery for BMs may be a confounding factor favoring patients with a better prognosis.

\section{Conclusions}

Our results support the use of GKS as a sole treatment for LC patients with BMs. Gamma Knife surgery itself does not negatively influence QOL as it is noninvasive and focal with a high local control rate and few complications. However, the cerebral part of the disease is particularly important for patients with LC. Quality of life changes and length of survival following GKS depend on BM volume. Careful follow-up and salvage GKS on demand seem to prevent a worsening of QOL due to relapse of BMs. Finally, the BRCS may be a useful and simple tool to predict survival before treatment selection. Further QOL studies according to the site of the primary cancer are warranted to identify subgroups of patients that will most benefit from treatment.

\section{Acknowledgments}

This study was supported by a grant from the Faculty of Medicine and Dentistry at the University of Bergen and a postdoctoral grant from Helse Vest.

\section{References}

1. Aoyama H, Tago M, Kato N, Toyoda T, Kenjyo M, Hirota $\mathrm{S}$, et al: Neurocognitive function of patients with brain metastasis who received either whole brain radiotherapy plus stereotactic radiosurgery or radiosurgery alone. Int J Radiat Oncol Biol Phys 68:1388-1395, 2007

2. Båtevik R, Grong K, Segadal L, Stangeland L: The female gender has a positive effect on survival independent of background life expectancy following surgical resection of primary non-small cell lung cancer: a study of absolute and relative survival over 15 years. Lung Cancer 47:173-181, 2005

3. Bonomi AE, Cella DF, Hahn EA, Bjordal K, Sperner-Unterweger B, Gangeri L, et al: Multilingual translation of the Functional Assessment of Cancer Therapy (FACT) quality of life measurement system. Qual Life Res 5:309-320, 1996

4. Braun DP, Gupta D, Staren ED: Quality of life assessment as a predictor of survival in non-small cell lung cancer. BMC Cancer 11:353, 2011

5. Breslow NE, Clayton DG: Approximate interference in generalized linear mixed models. J Am Stat Assoc 88:9-25, 1993

6. Brown PD, Jaeckle K, Ballman KV, Farace E, Cerhan JH, Anderson SK, et al: Effect of radiosurgery alone vs radiosur- 
gery with whole brain radiation therapy on cognitive function in patients with 1 to 3 brain metastases: a randomized clinical trial. JAMA 316:401-409, 2016

7. Cella DF, Tulsky DS, Gray G, Sarafian B, Linn E, Bonomi A, et al: The Functional Assessment of Cancer Therapy scale: development and validation of the general measure. J Clin Oncol 11:570-579, 1993

8. Chiou SM: Survival of brain metastatic patients treated with Gamma Knife radiosurgery alone. Clin Neurol Neurosurg 115:260-265, 2013

9. Chitapanarux I, Goss B, Vongtama R, Frighetto L, De Salles A, Selch M, et al: Prospective study of stereotactic radiosurgery without whole brain radiotherapy in patients with four or less brain metastases: incidence of intracranial progression and salvage radiotherapy. J Neurooncol 61:143-149, 2003

10. Cho KR, Lee MH, Kong DS, Seol HJ, Nam DH, Sun JM, et al: Outcome of Gamma Knife radiosurgery for metastatic brain tumors derived from non-small cell lung cancer. J Neurooncol 125:331-338, 2015

11. Corn BW, Moughan J, Knisely JP, Fox SW, Chakravarti A, Yung WK, et al: Prospective evaluation of quality of life and neurocognitive effects in patients with multiple brain metastases receiving whole-brain radiotherapy with or without thalidomide on Radiation Therapy Oncology Group (RTOG) trial 0118. Int J Radiat Oncol Biol Phys 71:71-78, 2008

12. Dharma-Wardene M, Au HJ, Hanson J, Dupere D, Hewitt J, Feeny D: Baseline FACT-G score is a predictor of survival for advanced lung cancer. Qual Life Res 13:1209-1216, 2004

13. Eisenhauer EA, Therasse P, Bogaerts J, Schwartz LH, Sargent D, Ford R, et al: New response evaluation criteria in solid tumours: revised RECIST guideline (version 1.1). Eur J Cancer 45:228-247, 2009

14. Fayers PM, Machin D: Quality of Life: The Assessment, Analysis and Interpretation of Patient-Reported Outcomes. Chichester, UK: Wiley, 2007

15. Ferrans CE, Zerwic JJ, Wilbur JE, Larson JL: Conceptual model of health-related quality of life. J Nurs Scholarsh 37:336-342, 2005

16. Habets EJ, Dirven L, Wiggenraad RG, Verbeek-de Kanter A, Lycklama À Nijeholt GJ, Zwinkels H, et al: Neurocognitive functioning and health-related quality of life in patients treated with stereotactic radiotherapy for brain metastases: a prospective study. Neuro Oncol 18:435-444, 2016

17. Harris S, Chan MD, Lovato JF, Ellis TL, Tatter SB, Bourland JD, et al: Gamma Knife stereotactic radiosurgery as salvage therapy after failure of whole-brain radiotherapy in patients with small-cell lung cancer. Int J Radiat Oncol Biol Phys 83:e53-e59, 2012

18. Idler EL, Benyamini Y: Self-rated health and mortality: a review of twenty-seven community studies. J Health Soc Behav 38:21-37, 1997

19. Iyer A, Harrison G, Kano H, Weiner GM, Luther N, Niranjan A, et al: Volumetric response to radiosurgery for brain metastasis varies by cell of origin. J Neurosurg 121:564-569, 2014

20. Kamangar F, Dores GM, Anderson WF: Patterns of cancer incidence, mortality, and prevalence across five continents: defining priorities to reduce cancer disparities in different geographic regions of the world. J Clin Oncol 24:2137-2150, 2006

21. Kondziolka D, Parry PV, Lunsford LD, Kano H, Flickinger JC, Rakfal S, et al: The accuracy of predicting survival in individual patients with cancer. J Neurosurg 120:24-30, 2014

22. Lemonnier I, Guillemin F, Arveux P, Clément-Duchêne C, Velten M, Woronoff-Lemsi MC, et al: Quality of life after the initial treatments of non-small cell lung cancer: a persistent predictor for patients' survival. Health Qual Life Outcomes 12:73, 2014
23. Lien K, Zeng L, Nguyen J, Cramarossa G, Cella D, Chang E, et al: FACT-Br for assessment of quality of life in patients receiving treatment for brain metastases: a literature review. Expert Rev Pharmacoecon Outcomes Res 11:701-708, 2011

24. Lin NU, Wefel JS, Lee EQ, Schiff D, van den Bent MJ, Soffietti R, et al: Challenges relating to solid tumour brain metastases in clinical trials, part 2: neurocognitive, neurologi$\mathrm{cal}$, and quality-of-life outcomes. A report from the RANO group. Lancet Oncol 14:e407-e416, 2013

25. Miller JA, Kotecha R, Barnett G, Suh JH, Angelov L, Murphy E, et al: Quality of Life Following GammaKnife radiosurgery for single and multiple brain metastases. Oncology (Williston Park) 30 (Suppl 4):S025, 2016 (Abstract)

26. Paules M, Casey M, Williams G, Swann RS, Murphy PS, Salazar VM, et al: Recommendations for capture, validation and summarisation of data from studies using RECIST. Eur J Cancer 47:697-701, 2011

27. Preusser M, Winkler F, Collette L, Haller S, Marreaud S, Soffietti R, et al: Trial design on prophylaxis and treatment of brain metastases: lessons learned from the EORTC Brain Metastases Strategic Meeting 2012. Eur J Cancer 48:3439_ 3447,2012

28. Rief H, Muley T, Bruckner T, Welzel T, Rieken S, Bischof M, et al: Survival and prognostic factors in non-small cell lung cancer patients with spinal bone metastases: a retrospective analysis of 303 patients. Strahlenther Onkol 190:59-63, 2014

29. Serizawa T, Higuchi Y, Nagano O, Hirai T, Ono J, Saeki N, et al: Testing different brain metastasis grading systems in stereotactic radiosurgery: Radiation Therapy Oncology Group's RPA, SIR, BSBM, GPA, and modified RPA. J Neurosurg 117 Suppl:31-37, 2012

30. Skeie BS, Eide GE, Flatebo M, Heggdal JI, Larsen E, Bragstad S, et al: Quality of life is maintained using Gamma Knife radiosurgery: a prospective study of a brain metastases patient cohort. J Neurosurg 126:708-725, 2017

31. Soffietti R, Kocher M, Abacioglu UM, Villa S, Fauchon F, Baumert BG, et al: A European Organisation for Research and Treatment of Cancer phase III trial of adjuvant wholebrain radiotherapy versus observation in patients with one to three brain metastases from solid tumors after surgical resection or radiosurgery: quality-of-life results. J Clin Oncol 31:65-72, 2013

32. Soffietti R, Rudā R, Mutani R: Management of brain metastases. J Neurol 249:1357-1369, 2002

33. Sperduto PW, Kased N, Roberge D, Xu Z, Shanley R, Luo X, et al: Summary report on the graded prognostic assessment: an accurate and facile diagnosis-specific tool to estimate survival for patients with brain metastases. J Clin Oncol 30:419-425, 2012

34. Suh JH: Stereotactic radiosurgery for the management of brain metastases. N Engl J Med 362:1119-1127, 2010

35. Thavarajah N, Bedard G, Zhang L, Cella D, Beaumont JL, Tsao M, et al: Psychometric validation of the functional assessment of cancer therapy-brain (FACT-Br) for assessing quality of life in patients with brain metastases. Support Care Cancer 22:1017-1028, 2014

36. Therasse P, Arbuck SG, Eisenhauer EA, Wanders J, Kaplan RS, Rubinstein L, et al: New guidelines to evaluate the response to treatment in solid tumors. European Organization for Research and Treatment of Cancer, National Cancer Institute of the United States, National Cancer Institute of Canada. J Natl Cancer Inst 92:205-216, 2000

37. Trifiletti DM, Lee CC, Schlesinger D, Larner JM, Xu Z, Sheehan JP: Leukoencephalopathy after stereotactic radiosurgery for brain metastases. Int J Radiat Oncol Biol Phys 93:870-878, 2015

38. Trotti A, Byhardt R, Stetz J, Gwede C, Corn B, Fu K, et al: 
Common toxicity criteria: version 2.0. An improved reference for grading the acute effects of cancer treatment: impact on radiotherapy. Int J Radiat Oncol Biol Phys 47:13-47, 2000

39. Weltman E, Salvajoli JV, Brandt RA, de Morais Hanriot R, Prisco FE, Cruz JC, et al: Radiosurgery for brain metastases: a score index for predicting prognosis. Int J Radiat Oncol Biol Phys 46:1155-1161, 2000

40. Wisnivesky JP, Halm EA: Sex differences in lung cancer survival: do tumors behave differently in elderly women? J Clin Oncol 25:1705-1712, 2007

41. Yamamoto M, Sato Y, Serizawa T, Kawabe T, Higuchi Y, Nagano O, et al: Subclassification of recursive partitioning analysis Class II patients with brain metastases treated radiosurgically. Int J Radiat Oncol Biol Phys 83:1399-1405, 2012

\section{Disclosures}

The authors report no conflict of interest concerning the materials or methods used in this study or the findings specified in this paper.

\section{Author Contributions}

Conception and design: BS Skeie, Bragstad, Flateb $\varnothing$, Natvig, Eide, GO Skeie. Acquisition of data: BS Skeie, Bragstad, Flateb $\varnothing$. Analysis and interpretation of data: BS Skeie, Bragstad, Natvig, GO Skeie, Behbahani, Pedersen, Enger. Drafting the article: BS Skeie, Bragstad, Flateb $\emptyset$, Natvig, GO Skeie, Behbahani. Critically revising the article: all authors. Reviewed submitted version of manuscript: all authors. Approved the final version of the manuscript on behalf of all authors: BS Skeie. Statistical analysis: BS Skeie, Bragstad, Eide. Study supervision: BS Skeie, Natvig.

\section{Supplemental Information}

\section{Previous Presentations}

Portions of this work were presented in abstract form at the 12th Biennial Congress of the International Stereotactic Radiosurgery Society held in Yokohama, Japan, in June 2015.

\section{Correspondence}

Bente Sandvei Skeie, Department of Neurosurgery, Haukeland University Hospital, Jonas Lies vei 1, Bergen N-5021, Norway. email: bsai@helse-bergen.no. 